\title{
COMPREHENSIVE MANAGEMENT OF EMPHYSEMATOUS PYELONEPHRITIS, OUR INSTITUTIONAL EXPERIENCE- A DESCRIPTIVE STUDY
}

\author{
Periasamy Ponnusamy11, Sivashankar Govindaraju2, Senthilkumar Kandeban ${ }^{3}$
}

1Professor, Department of Urology, Government Kilpauk Medical College Hospital, Chennai, Tamilnadu.

2Professor, Department of Urology, Government Kilpauk Medical College Hospital, Chennai, Tamilnadu.

${ }_{3}^{3}$ Mch Postgraduate Student, Department of Urology, Government Kilpauk Medical College Hospital, Chennai, Tamilnadu.

\section{ABSTRACT}

\section{BACKGROUND}

Emphysematous pyelonephritis (EPN) is a severe necrotising infection of the renal parenchyma and perirenal tissue. It is a urological emergency.

Aims and Objectives- Our aim is to study comprehensive management of emphysematous pyelonephritis.

\section{MATERIALS AND METHODS}

This is a study of three years period at our hospitals (Government Kilpauk Medical College and Government Royapettah Hospital). Total 29 cases of Emphysematous pyelonephritis have been treated medically (conservatively) and surgically.

\section{RESULTS}

Patients were treated conservatively (medical management) and/or surgically in the form of DJ stenting, percutaneous drainage and nephrectomy.

\section{CONCLUSION}

Early diagnosis and effective management can prevent mortality.

\section{KEY WORDS}

Emphysematous Pyelonephritis, Double J Stenting, Percutaneous Drainage.

HOW TO CITE THIS ARTICLE: Ponnusamy P, Govindaraju S, Kandeban S. Comprehensive management of emphysematous pyelonephritis, our institutional experience- a descriptive study. J. Evolution Med. Dent. Sci. 2018;7(19):2317-2319, DOI: $10.14260 /$ jemds/2018/522

\section{BACKGROUND}

Emphysematous pyelonephritis (EPN) is a severe necrotising infection of the renal parenchyma ${ }^{1}$ and perirenal tissue. It is a urological emergency. It causes gas formation within the collecting system, renal parenchyma and perirenal tissues. ${ }^{2}$ Gas in the renal pelvis alone without parenchymal gas is often referred to as emphysematous pyelitis. Emphysematous pyelonephritis is common in uncontrolled diabetes and immunocompromised patients and common in females (prone for recurrent UTI). Obstructing calculus, cause of EPN in non-diabetes patients.

Emphysematous pyelonephritis is rapidly progressive, requiring appropriate therapy to salvage the infected kidney. ${ }^{3}$ The clinical course of Emphysematous pyelonephritis can be severe and life-threatening if not recognised early and treated promptly. Identification of the adverse prognostic factors like elevated serum creatinine, shock, thrombocytopenia or altered sensorium are important for its successful management. The objective of the study was to evaluate aetiology and various management options in the treatment of Emphysematous pyelonephritis.

'Financial or Other Competing Interest': None.

Submission 10-04-2018, Peer Review 22-04-2018,

Acceptance 24-04-2018, Published 07-05-2018.

Corresponding Author:

Dr. Periasamy Ponnusamy,

Department of Urology, $5^{\text {th }}$ Floor, Surgical Block,

Government Kilpauk Medical College \& Hospital,

Kilpauk, Chennai, Tamilnadu.

E-mail: drppsamysubha@gmail.com

DOI: $10.14260 /$ jemds/2018/522

\section{(c) $(1)(5)$}

\section{MATERIALS AND METHODS}

It is the descriptive study. About the patients admitted with Emphysematous pyelonephritis in Kilpauk Medical College and Govt. Royapettah Hospital during the period of last three years (2014 - 2017).

29 cases of emphysematous pyelonephritis admitted during Aug. 2014 - July 2017 and investigated with biochemical parameters, x-ray, ultrasound and CT KUB and functional status assessed by DMSA Renogram.

\section{RESULTS}

Among 29 cases of Emphysematous pyelonephritis, patients with features of septic shock managed in intensive care unit with higher antibiotics, fluid and electrolyte imbalance management, insulin therapy in case of elevated blood sugar in diabetes patients and haemodialysis done based on renal parameters. Almost $90 \%$ are diabetics and $10 \%$ are nondiabetics and only $10 \%$ cases underwent dialysis.

In our study 23 cases were females, 6 cases were males. Left kidney was affected more commonly about $74 \%$ than right kidney. Right kidney involvement was seen in $20 \%$ and bilateral involvement in $6 \%$ of cases. Emphysematous pyelonephritis is more common in patients more than 40 years of age, only 5 cases has been reported below 40 years of age, 12 cases were in between 40 - 60 years and 12 cases has been reported in above 60 years of age.

Most common organism causing Emphysematous pyelonephritis in our study was E. coli infection (Reported in 22 cases) followed by Klebsiella infection in 5 cases, other organisms seen in 2 cases. 


\section{Management}

Three cases with class 1 (Classification by Huang and Tseng ${ }^{3}$ ) emphysematous pyelonephritis were managed conservatively with higher broad-spectrum antibiotics and supportive care. Nine cases with class 2 were managed surgically in the form of DJ stenting and Percutaneous drainage (PCD). Eight cases of class $3 \mathrm{~A}$ and Seven cases of class $3 \mathrm{~B}$ also initially managed with DJ stenting and PCD, but Three cases of class $3 \mathrm{~A}$ and Four cases of class $3 \mathrm{~B}$ ended in subcapsular nephrectomy. Two cases of class 4 were managed with DJ stenting and PCD.

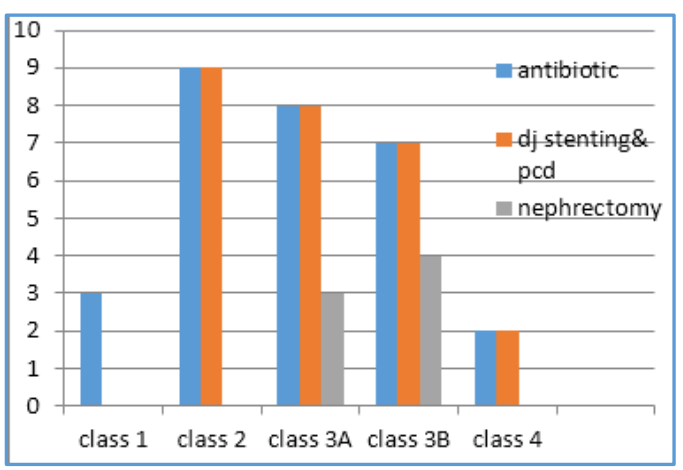

Table 1. Management

Some of our case scenario are discussed below.

Case 1- 38 years old female had Emphysematous pyelonephritis class 2, managed with DJ stenting and Antibiotics.

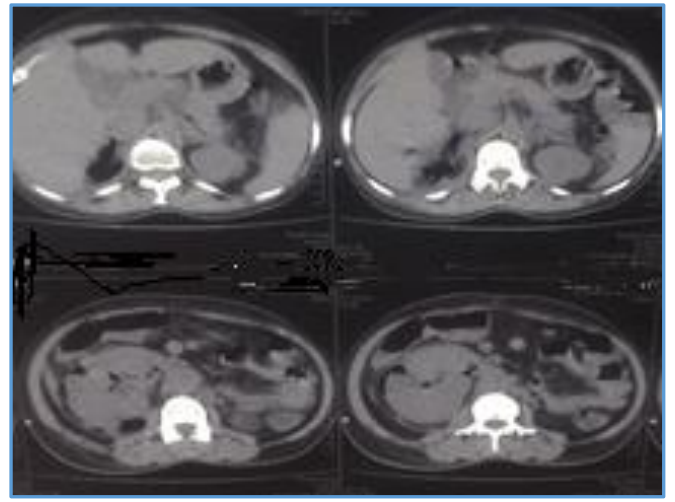

Case 2- 52 years old female with diabetes had Emphysematous pyelonephritis class $3 \mathrm{~A}$, managed initially with percutaneous drainage and later subcapsular nephrectomy done following DMSA.

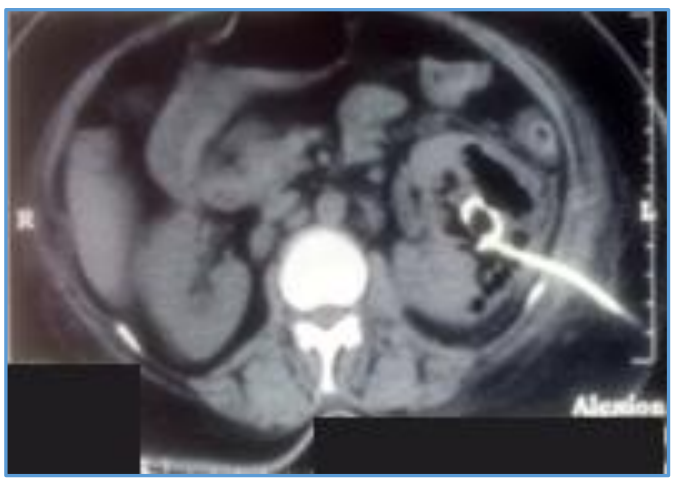

Case 3- 55 years old female with diabetes had Emphysematous pyelonephritis class 3B type, percutaneous drainage done initially and then subcapsular nephrectomy done following Renogram.

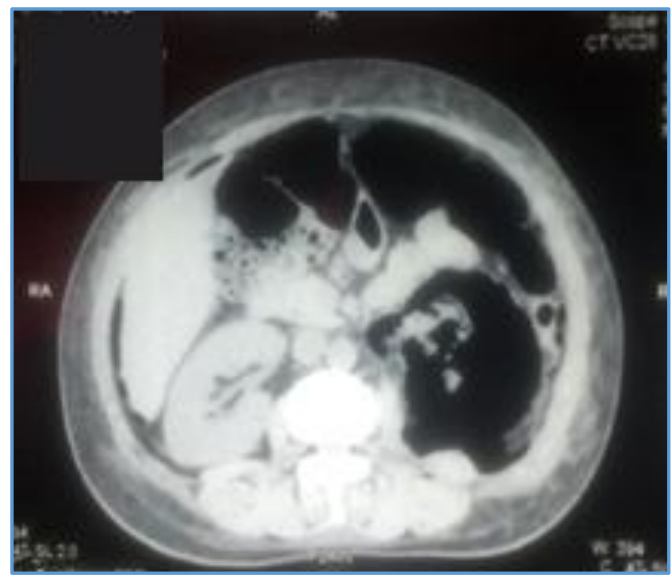

\section{DISCUSSION}

Most common aetiology of Emphysematous pyelonephritis is due to E. coli followed by Klebsiella species, less commonly by Proteus, Pseudomonas, Streptococcus, Entamoeba histolytica, Aspergillus fumigatus and Clostridium Candida species have also been isolated in patients with Emphysematous pyelonephritis.

Classification by Huang and Tseng, ${ }^{2}$ as per CT images are Class 1: Gas in collecting system only, Class 2: Gas in parenchymal tissue, Class 3A: Extension of gas into perinephric space, Class 3B: Extension of gas into pararenal space and Class 4: Emphysematous pyelonephritis in solitary kidney or bilateral disease. The pathogenesis of gas formation requires pathogenic bacteria capable of mixed acid fermentation, hyperglycaemic environment in case of diabetes and localised tissue ischaemia. Because a hyperglycaemic environment is one of the requirements in gas formation, it only makes sense that diabetes is a significant predisposing factor. It has been estimated that upto $95 \%$ of Emphysematous pyelonephritis cases have underlying uncontrolled diabetes mellitus. ${ }^{4}$ Hyperglycaemia in association with impaired blood supply to the kidneys from vasculopathy- both of which are prevalent in diabetic patients- facilitates the process of anaerobic metabolism. ${ }^{5}$ Other predisposing factors such as ureteric obstruction commonly due to calculus or immunological impairment. ${ }^{6} \mathrm{On}$ histopathology is widespread microabscesses, interstitial inflammation, glomerulosclerosis and sloughed papillae are seen. The clinical approach to treating patients with Emphysematous pyelonephritis has changed over the years. Due to advances in medical imaging, interventional radiology, newer more effective antibiotic therapy and readily available intensive care integrated with dialysis support, patients with Emphysematous pyelonephritis have much better outcomes. Managing Emphysematous pyelonephritis more conservatively and DJ stenting has thus become the standard of care. ${ }^{7}$ In our centre patients were treated with broadspectrum antibiotics, based on urine and PCD fluid culture results. Recent reviews of the management of Emphysematous pyelonephritis propose that percutaneous drainage should be part of the initial management strategy for Emphysematous pyelonephritis. ${ }^{8}$ In patients with 
extensive/fulminant disease with haemodynamic compromise many have determined that together with fluid resuscitation and antibiotics, immediate nephrectomy should not be delayed for the successful management of Emphysematous pyelonephritis. ${ }^{9-11}$ But in our study, patients with haemodynamic instability treated with supportive measures in intensive care unit and delayed subcapsular nephrectomy was done after assessing functional status by DMSA Renogram. Poor prognostic factors include thrombocytopenia, altered consciousness, shock and acute renal failure. ${ }^{12}$

\section{CONCLUSION}

In recent days, number of cases of emphysematous pyelonephritis is increasing due to increased incidence of diabetes mellitus, but the mortality rate decreased dramatically and is rare due to early diagnosis and effective management with available higher antibiotics and fluid and electrolyte imbalance management, early surgical intervention in the form of DJ stenting, percutaneous drainage and subcapsular nephrectomy done in rare cases. In our study, mortality is nil.

\section{REFERENCES}

[1] Costas S. Renal and perirenal emphysema. Br J Urol 1972;44(3):311-9.

[2] Huang JJ, Tseng CC. Emphysematous pyelonephritis: clinicoradiological classification, management, prognosis and pathogenesis. Arch Intern Med 2000;160(6):797-805.

[3] Arsene C, Saste A, Arul S, et al. A case series of emphysematous pyelonephritis. Article ID 587926, Case Reports in Med 2014;2014: p. 6.
[4] Ubee SS, McGlynn L, Fordham M. Emphysematous pyelonephritis. BJU International 2011;107(9):1474-8.

[5] Tang HJ, Li CM, Yen MY, et al. Clinical characteristics of emphysematous pyelonephritis. Journal of Microbiology, Immunology and Infection 2001;34(2):125-30.

[6] Vivek V, Panda A, Devasia A. Emphysematous pyelonephritis in a renal transplant recipient-is it possible to salvage the graft? Annals of Transplant 2012;17(3):138-41.

[7] Fatima R, Jha R, Muthukrishnan J, et al. Emphysematous pyelonephritis: a single centre study. Indian Journal of Nephrology 2013;23(2):119-24.

[8] Pontin AR, Barnes RD. Current management of emphysematous pyelonephritis. Nature Reviews Urology 2009;6(5):272-9.

[9] Gautam G. Re: Is percutaneous drainage the new gold standard in the management of emphysematous pyelonephritis? Evidence from a systematic review: Journal of Urology 2009;181(1):411-12.

[10] Ahlering TE, Boyd SD, Hamilton CL, et al. Emphysematous pyelonephritis: a 5-year experience with 13 patients. Journal of Urology 1985;134(6):1086-8.

[11] Pontin AR, Barnes RD, Joffe J, et al. Emphysematous pyelonephritis in diabetic patients. British Journal of Urology 1995;75(1):71-4.

[12] Kapoor R, Muruganandham K, Gulia AK, et al. Predictive factors for mortality and need for nephrectomy in patients with emphysematous pyelonephritis. BJU Int 2010;105(7):986-9. 